\title{
Wave induced instantaneously-liquefied soil depth in a non-cohesive seabed
}

\author{
Wen-Gang Qi ${ }^{\text {a,b }}$, Fu-Ping Gao ${ }^{\text {a,b,* }}$ \\ ${ }^{a}$ Key Laboratory for Mechanics in Fluid Solid Coupling Systems, Institute of Mechanics, Chinese Academy of Sciences, Beijing, 100190, China \\ ${ }^{\mathrm{b}}$ School of Engineering Science, University of Chinese Academy of Sciences, Beijing 100049, China
}

\section{A R T I C L E I N F O}

\section{Keywords:}

Wave-induced liquefaction

Pore-pressure distribution

Instantaneous liquefaction

Liquefaction depth

Analytical solution

\begin{abstract}
A B S T R A C T
Instantaneous liquefaction can be induced by the upward seepage force generated in a sandy seabed under wave troughs. The wave-induced pore-pressure distribution in the non-cohesive seabed with an instantaneouslyliquefied layer is investigated analytically. Based on the analytical solution to Biot's consolidation equations for the response of a poro-elastic bed to water waves, the expressions of liquefied soil depth are derived with modifying the criterion for instantaneous liquefaction, which is verified with existing offshore field observations and multi-scale numerical simulations. Analytical investigation indicates that, in the instantaneously-liquefied soil layer, the buoyant weight of soil is essentially balanced by upward seepage force into a quasi-static state. Underneath the fully liquefied layer, the effective stress can be remarkably reduced. An excess pore-pressure ratio is then proposed to quantitatively evaluate the instantaneous liquefaction degree and its corresponding influential depth. Parametric studies indicate that, for a certain excess pore-pressure ratio, the influential depth decreases with increasing saturation degree, permeability of soil or water depth, but increases with increasing wave height. The influential depth of a non-cohesive seabed under waves increases significantly with reducing the threshold value of excess pore-pressure ratio, which may have much influence on the stability design for submarine structures.
\end{abstract}

\section{Introduction}

In the wave-dominated coastal locations or the surf zones, seabed liquefaction can take place during severe storms. Wave-induced excess pore-pressure and the resulting loss of soil strength could produce catastrophic consequences to marine structures, e.g., the sinking or floatation of pipelines (Sumer et al., 1999; Qi et al., 2017), the instability of breakwaters (Groot et al., 2006), and the local scour around pile foundations (Qi and Gao, 2014). Liquefied soil depth should be well evaluated in the foundation design for marine structures.

As for the pore-pressure responses to waves, two primary mechanisms, including oscillatory and residual pore-pressure, have been observed in flume experiments and offshore in-situ measurements (see Zen and Yamazaki, 1990a). The residual pore-pressure, i.e. the buildup of excess pore-pressure, is mainly induced by the compression tendency of soil skeleton while the cyclic wave loading is being exerted. It has been well recognized that residual liquefaction may be initiated once the effective stress of soil is reduced to zero while the residual pore-pressure is being increased, which corresponds to a complete loss of shear strength (see Sumer, 2014).

In contrast to the residual liquefaction, the instantaneous liquefaction (also termed as "momentary liquefaction") is induced essentially by the upward seepage force in the upper layer of the seabed under wave troughs. Similar to the quicksand phenomenon, the instantaneous liquefaction is particularly prone to occur in a sandy or non-plastic silty seabed. In the state of instantaneous liquefaction, the buoyant weight of soil is totally balanced by the seepage force and the confining stress would vanish consequently.

In the past a few decades, several analytical solutions have been obtained for wave-induced oscillatory pore-pressure responses. Under the assumption of a permeable rigid seabed with incompressible pore-water, Putnam (1949) presented an analytical solution for wave-induced oscillatory pore-pressure in an isotropic seabed with finite thickness, which was described by Laplace's equation as a potential flow. Diffusion equation was later employed for describing compressible pore-water in a hydraulically isotropic rigid seabed (Moshagen and Torum, 1975). On the basis of Biot's theory framework for porous elastic media, a few porous models for wave-seabed interactions have been established under various assumptions (see Sumer, 2014). Among them, the analytical solution by Yamamoto et al. (1978) took into account of compressible pore-water in a compressible isotropic porous seabed with infinite thickness. Madsen (1978) presented general analytical methods for pore

\footnotetext{
* Corresponding author. Key Laboratory for Mechanics in Fluid Solid Coupling Systems, Institute of Mechanics, Chinese Academy of Sciences, Beijing, 100190, China.

E-mail address: fpgao@imech.ac.cn (F.-P. Gao).
} 
pressures and effective stresses in a homogeneous porous seabed of arbitrary thickness as well as in a horizontally layered seabed. Hsu and Jeng (1994) later derived the analytical solution to Biot's equations for the case of finite soil thickness, which can converge to the above solution by Yamamoto et al. (1978) while the soil thickness gets large enough. Besides analytical analyses, numerical modeling was also employed to investigate wave-induced oscillatory pore-pressure under complex boundary and wave conditions, e.g. Mase et al. (1994), Cheng et al. (2001), Higuera et al. (2014), Sui et al. (2016, 2017) and Zhang et al. (2016). It was indicated that the numerical results (e.g. Cheng et al., 2001) by solving Biot's equations are in good agreement with the above analytical solutions (see Sumer, 2014).

Accurate evaluation of instantaneously-liquefied soil depth is crucial for the design of submarine foundations. Sakai et al. (1992) analytically investigated (revised later by Law (1993)) the liquefied soil depth of a sandy seabed under waves, adopting the boundary-layer approximation by Mei and Foda (1981). The liquefied soil depth was evaluated with "iteration calculation method": if the vertical effective stress at a certain tentative depth becomes negative, the tentative depth is further increased and the calculation is repeated until the vertical effective stress approaches zero to finally determine the liquefaction depth (see Sakai et al., 1992). In such an iteration calculation, the force balance at the soil element-scale could not be strictly satisfied, which will be detailed in Section 2.

The analytical results by Sakai et al. (1992) indicated that it would be difficult to reproduce instantaneous liquefaction in a small-size wave flume using a normal sand bed (e.g. silica sand). As such, offshore in-situ tests play a vital role for understanding the phenomenon of instantaneous liquefaction. The wave-induced instantaneous liquefaction was observed in the offshore field by Mory et al. (2007). In their field observations, the pore-pressure responses at different depths of the sandy seabed were continuously measured. High pore-pressure gradients were generated in the seabed, resulting in a number of instantaneous liquefaction events. The instantaneous liquefaction was found to be quite sensitive to the presence of gas content in the sands, which enhances the compressibility of the porous seabed (Gratiot and Mory, 2000). Following the field observations by Mory et al. (2007), Michallet et al. (2009) further analyzed the same field data to examine the effects of saturation degree (approximately ranging from 0.950 to 0.995 ) on the pore-pressure responses under waves. For such high saturation degree, it would be reasonable to consider the entrapped gas content as the constituent part of the pore-water (Groot et al., 2006), and thereby to assume the sandy seabed as a two-phase media with variable pore-water compressibility to reflect the effect of saturation degree. In addition, the cylindrical-shaped apparatuses were ever employed (Zen and Yamazaki, 1990b; Chowdhury et al., 2006; Liu et al., 2015) for one-dimensional simulations of the wave-seabed interaction to understand the upward seepage induced liquefaction as a kind of quicksand.

There exist two typical criteria to evaluate the critical state for waveinduced instantaneous liquefaction:

(1) The criterion (denoted as "criterion-I") firstly proposed by Bear (1972) was from the perspective of soil-element scale. The vertical gradient of excess pore-pressure $j_{\mathrm{z}}(=d p / d z)$, inducing the upward seepage force in the instantaneously-liquefied soil layer under wave troughs, must locally overcome the buoyant unit weight of soil $\left(\gamma^{\prime}\right)$, i.e.

$j_{z}-\gamma^{\prime} \geq 0$

where $\gamma^{\prime}=\left(G_{\mathrm{s}}-1\right)(1-n) \gamma_{\mathrm{w}}$ (in $\mathrm{kN} / \mathrm{m}^{3}$ ), which can be obtained according to the phase relationships between soil particles and pore water (see Craig (2004)), $G_{s}$ is the specific gravity of sand particles, $n$ is the porosity of the sand $(n=e /(1+e)$, in which $e$ is the void ratio of the sand, i.e. the ratio of the volume of voids to the volume of solid particles), $\gamma_{\mathrm{w}}$ is the unit weight of water (in $\mathrm{kN} / \mathrm{m}^{3}$ ). Note that the positive value of
" $j_{\mathrm{z}}$ " indicates that the seepage force is upward (z-axis is downward).

(2) The other criterion for instantaneous liquefaction (denoted as "criterion-II") was later deduced by Zen and Yamazaki (1990a) from the force analysis on the vertical soil-column rather than the above analysis on soil-element in the criterion-I. The criterion-II can be expressed with the following inequality:

$p(z)-P_{\mathrm{b}} \geq \sigma_{z 0}^{\prime}$

where $p(z)$ is the wave-induced transient pore-pressure at the depth $(z)$ in the seabed; $P_{\mathrm{b}}$ is the wave-induced pressure (negative under wave troughs) at the seabed surface $(z=0) ; \sigma_{z 0}^{\prime}\left(=\gamma^{\prime} z\right)$ is the initial vertical effective stress for a homogenous sandy seabed. The criterion-II implies that instantaneous liquefaction may occur when the excess pore-pressure difference between a certain depth and the soil surface becomes greater than the overburden soil pressure.

Note that, if adopting the existing criteria for instantaneous liquefaction, an upward resultant force would be induced unreasonably in a sandy (non-cohesive) seabed, which will be detailed in Section 2.

In this study, the vertical distribution of wave-induced pore-pressure in a non-cohesive seabed with instantaneously-liquefied layer will be investigated analytically. Based on the classical solution to Biot's consolidation equations for porous media, the expressions for liquefied soil depth are derived with modifying the liquefaction criterion. Parametric study is further made to investigate the influential factors for liquefied soil depth.

\section{Wave-induced excess pore-pressure and instantaneous liquefaction: analytical investigation}

\subsection{Re-examination of excess pore-pressure distribution by using existing liquefaction criteria: A case study}

To examine the excess pore-pressure distribution in an instantaneously-liquefied sandy seabed, a case study is made for the given values of wave parameters and soil properties as follows: The water depth $h=10.0 \mathrm{~m}$, the wave height $H=3.0 \mathrm{~m}$, the wave period $T=8.0 \mathrm{~s}$ and the wave length $L \approx 70.9 \mathrm{~m}$; the coefficient of permeability of the sand $k_{\mathrm{s}}=1.0 \times 10^{-4} \mathrm{~m} / \mathrm{s}$, the soil elasticity modulus $E=30.0 \mathrm{MPa}, \gamma^{\prime}=$ $8.82 \mathrm{kN} / \mathrm{m}^{3}$, the saturation degree $S_{\mathrm{r}}=0.98, n=0.45$, and the Poisson ratio of the sand $\nu=0.3$.

As mentioned in Section 1, the liquefied soil depth used to be evaluated with the "iteration calculation method", once the distribution of excess pore-pressure under wave troughs are obtained, and at the same time the liquefaction criterion is chosen as the criterion-I (Eq. (1)) or the criterion-II (Eq. (2)). The analytical solution by Yamamoto et al. (1978) (referred as "Yamamoto solution" later, see Appendix A) is employed for calculating the wave-induced excess pore-pressure in a poro-elastic seabed.

Fig. 1 gives the vertical distribution of the excess pore-pressure difference $\left(p-P_{\mathrm{b}}\right)$ under wave troughs calculated with the solution by Yamamoto et al. (1978). The vertical distribution of the initial vertical effective stress $\sigma_{z 0}^{\prime}\left(=\gamma^{\prime} z\right)$ in the homogeneous sandy seabed is also provided in this figure. When adopting the different criterion for instantaneous liquefaction (criterion-I or criterion-II), the calculated values of liquefaction depth are different, denoted as " $z_{\mathrm{s}}$ " for the criterion-I, and " $z_{\mathrm{p}}$ " for the criterion-II, respectively (see Fig. 1). As indicated in the expressions for the existing liquefaction criteria (Eqs. (1) and (2)), the liquefaction depth $z_{\mathrm{s}}(=0.45 \mathrm{~m}$; under the given wave and soil conditions in this case study) is obtained according to the effective stress analysis on soil-element, i.e. Eq. (1) for the criterion-I; whereas $z_{\mathrm{p}}$ $(=0.93 \mathrm{~m})$ was derived from the force balance of the "soil-column AB" see Fig. 1, i.e. Eq. (2) for the criterion-II.

As shown in Fig. 1, for the selected three typical elements (i.e. the element-1, -2 and -3 ) at various depths, only the elememt-2 (where 

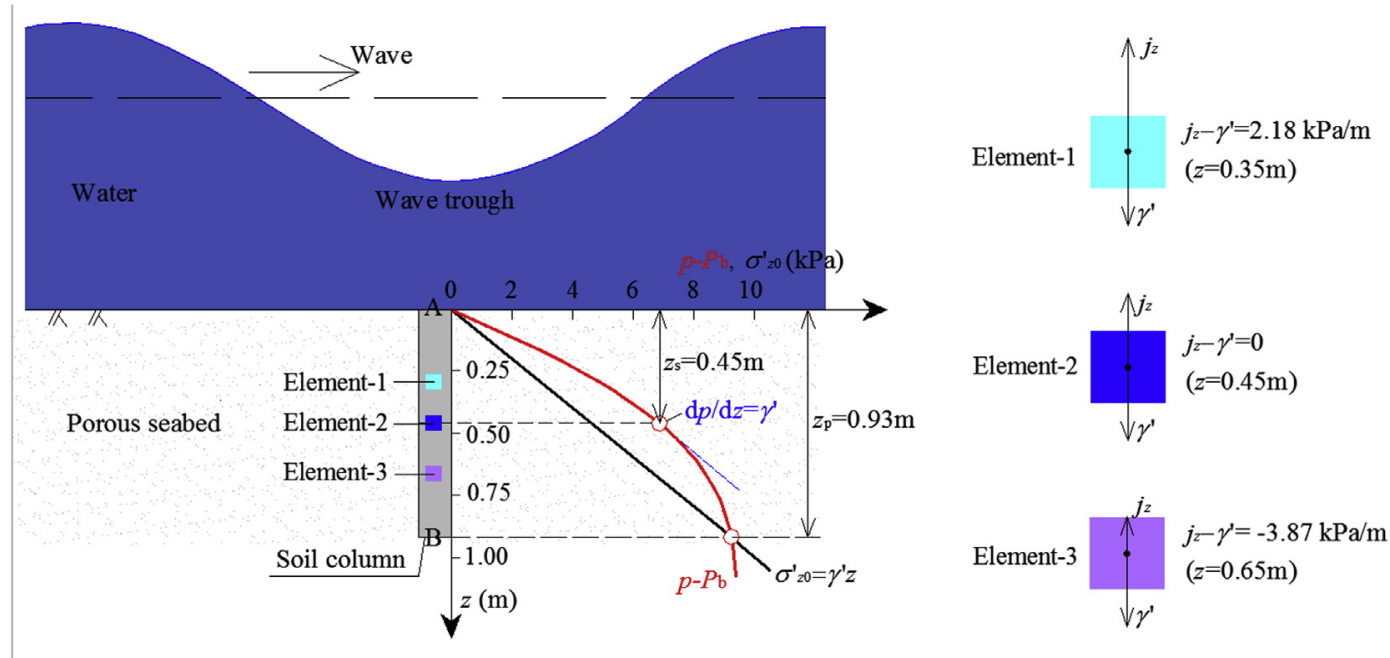

Fig. 1. The vertical distributions of $\left(p-P_{\mathrm{b}}\right), \sigma_{z 0}^{\prime}$, and the corresponding instantaneously-liquefied soil depths evaluated with the existing two liquefaction criteria, i.e. Eq. (1) and Eq. (2), respectively.

$\left.j_{z}(=d p / d z)=\gamma^{\prime}\right)$ is satisfied locally for the balance between the upward seepage force and the downward buoyant unit weight of the soil element $\left(j_{\mathrm{z}}-\gamma^{\prime}=0\right)$. The arbitrary soil elements located between $z=z_{\mathrm{s}}$ and $z_{\mathrm{p}}$ (e.g., the element-3) are partially-liquefied, where a downward resultant force exists $\left(j_{\mathrm{z}}-\gamma^{\prime}<0\right)$. In contrast, for an arbitrary soil element located between $z=0$ and $z_{\mathrm{s}}$ (e.g., the element-1), an upward resultant force would be generated $\left(j_{z}-\gamma^{\prime}>0\right)$ and thereby the upper layer of soil mass would be sucked away, which is however fallacious in physics. Therefore, the existing expressions for wave-induced pore-pressure in an instantaneously-liquefied sandy seabed need to be modified.

\subsection{Excess pore-pressure distribution in the instantaneously-liquefied sandy seabed}

\subsubsection{Instantaneously-liquefied soil depth: derivation}

As the cyclic loading on the porous seabed, storm waves are generally characterized by low frequencies $(\sim 0.1 \mathrm{~Hz})$ and many cycles $\left(\sim 10^{3}\right.$ or more). Ulker et al. (2009) ever made a systematic study of the inertia effect on wave-induced seabed responses by developing three formulations, termed as fully dynamic, partly dynamic, and quasi-static formulation, respectively. It has been indicated that the inertia effect from the accelerations of soil skeleton and pore water can be increased to a certain extent with increasing soil permeability. But the difference between the fully dynamic solution and that for the quasi-static appears to be less than $5 \%$ at most (Ulker et al., 2009). These analytical results were in accord with the points of Cheng and Liu (1986) that the inertia effect can be ignored for most wave-induced seabed responses, particularly for those involving fine sediments relevant to liquefaction processes (see Sumer, 2014). So, in the instantaneously-liquefied seabed, the buoyant unit weight of the soil $\left(\gamma^{\prime}\right)$ can be assumed to be totally balanced by the vertical gradient of excess pore-pressure $\left(j_{z}\right)$ :

$j_{z}-\gamma^{\prime} \cong 0$

This criterion (Eq. (3a,b)) for instantaneous liquefaction will be verified by the comparative studies in Section 3. Submitting the equations of $j_{\mathrm{z}}=d p / d z$ and $\gamma^{\prime}=\left(G_{\mathrm{s}}-1\right)(1-n) \gamma_{\mathrm{w}}$ into Eq. (3a,b), the excess pore-pressure gradient in the instantaneously-liquefied layer can be expressed as

$\frac{d p}{d z}=\left(G_{\mathrm{s}}-1\right)(1-n) \gamma_{\mathrm{w}}$

At arbitrary locations in the instantaneously-liquefied layer $(0 \leq z<$ $z_{l}, z_{l}$ is the liquefaction depth), the resultant effective overburden stress would vanish consequently: $\sigma_{z}^{\prime}(z)=\int_{0}^{z}\left(\gamma^{\prime}-j_{z}\right) \mathrm{d} z=0$. The waveinduced pore-pressure in the instantaneously-liquefied layer $p(z)$ can then be obtained:

$p(z)=P_{\mathrm{b}}+\gamma^{\prime} z \quad\left(0 \leq z<z_{l}\right)$

where $P_{\mathrm{b}}$ is the wave-induced pore pressure at the seabed surface. Thus, the previous criterion-I (Eq. (1)) and criterion-II (Eq. (2)) are identical, when the present criterion (Eq. (3a,b)) is adopted. Based on the linear approximation of wave theory, $P_{\mathrm{b}}$ can be calculated with

$P_{\mathrm{b}}=p_{0} \cos (\lambda x+\omega t)$

in which $p_{0}\left(=0.5 \gamma_{\mathrm{w}} H / \cosh (\lambda h)\right)$ is the amplitude of the excess pressure at the seabed surface ( $z=0), \gamma_{\mathrm{w}}$ is the unit weight of water, $\lambda(=2 \pi / L)$ is the wave number, $\omega(=2 \pi / T)$ is the angular frequency of waves and $t$ is the time. From Eq. (4), the wave-induced pore pressure at the interface between the instantaneously-liquefied layer and the underlying soil $\left(z=z_{l}\right)$ can then be obtained as

$P_{\mathrm{b}}^{\prime}=\left.p(z)\right|_{z=z_{l}}=P_{\mathrm{b}}+\gamma^{\prime} z_{l}$

As demonstrated in the case study in Section 2.1, the evaluated instantaneously-liquefied soil depth $\left(z_{\mathrm{p}}=0.93 \mathrm{~m}\right)$ is much smaller than the wave length $(L \approx 70.9 \mathrm{~m})$, i.e., $z_{\mathrm{p}} / L \ll 1.0$, so the interface between the instantaneously-liquefied layer and the underlying sand is approximately horizontal. Adopting Eq. (6) as the pressure boundary condition at $z=z_{l}$, the wave-induced pore-pressure in the unliquefied sand $\left(z \geq z_{l}\right)$ can then be described with Yamamoto solution (see Appendix A). That is, the wave-induced pore-pressure in the unliquefied sand layer can be calculated with Eq. (A5) in Appendix A:

$p(z)=P_{\mathrm{b}}\left[(1-\alpha) \exp (-\lambda z)+\alpha \exp \left(-\lambda^{\prime} z\right)\right]$

Replacing " $P_{\mathrm{b}}$ " and " $z$ " in Eq. (7) with " $P_{\mathrm{b}}^{\prime}$ " and " $z-z_{l}$ ", respectively, the vertical distribution of wave-induced pore-pressure in the seabed with an instantaneously-liquefied layer can be described with the following piecewise function:

$p(z)= \begin{cases}P_{\mathrm{b}}+\gamma^{\prime} z & \left(0 \leq z<z_{l}\right) \\ P^{\prime}{ }_{\mathrm{b}}\left\{(1-\alpha) \exp \left[-\lambda\left(z-z_{l}\right)\right]+\alpha \exp \left[-\lambda^{\prime}\left(z-z_{l}\right)\right]\right\} & \left(z \geq z_{l}\right)\end{cases}$

where $\alpha$ and $\lambda^{\prime}$ are the coefficients related to the properties of the soil and waves, which are detailed in Appendix A.

The instantaneous liquefaction is in nature a quasi-static response of 
the porous seabed, where the effective stress is periodically reduced to nil by the upward seepage force under wave troughs. In such a quasi-static process, the permeability coefficient of the sandy seabed can be regarded as remaining unchanged, although the upward seepage may loosen the sand layer to a certain extent, especially near the seabed surface. It has been realized that the permeability coefficient $\left(k_{s}\right)$ of the sand is mainly relevant to the effective diameter of sand particles $d_{10}$ (in $\mathrm{mm}$ ) and can be evaluated with Hazen's equation, i.e. $k_{\mathrm{s}}=10^{-2} d_{10}^{2}\left(\mathrm{in} \mathrm{m} / \mathrm{s}^{2}\right)$ (see Craig, 2004). Meanwhile, at the interface between the instantaneously-liquefied layer and the underlying unliquefied soil $\left(z=z_{l}\right)$, both the wave-induced pore-pressure and the upward seepage velocity $\left(u_{\mathrm{z}}=-k_{\mathrm{s}} \mathrm{d} p\right.$, i.e. Darcy's law) should be continuous. As such, both the continuity and the derivability in mathematics for the excess pore-pressure $p(z)$ should be satisfied accordingly at the junction point of the piecewise function (Eqs. (8a) ( $8 b)$ ).

(1) The continuity of excess pore-pressure: submitting $z=z_{l}$ into Eqs (8a) and (8b), then

$\left.\left(P_{\mathrm{b}}+\gamma^{\prime} z\right)\right|_{z=z_{l}}=\left.P_{\mathrm{b}}^{\prime}\left\{(1-\alpha) \exp \left[-\lambda\left(z-z_{l}\right)\right]+\alpha \exp \left[-\lambda^{\prime}\left(z-z_{l}\right)\right]\right\}\right|_{z=z_{l}}$

i.e. $P_{\mathrm{b}}+\gamma^{\prime} z_{l}=P_{\mathrm{b}}^{\prime}$ (see Eq. (6)), which is actually the expression for the wave-induced pressure at the interface between the instantaneouslyliquefied and the underlying unliquefied layers.

(2) The continuity of the derivative of excess pore-pressure: performing differentiation to the right terms of Eqs. (8a) and (8b), respectively, then

$\gamma^{\prime}=\left(-P_{\mathrm{b}}-\gamma^{\prime} z_{l}\right)\left[\lambda(1-\alpha)+\lambda^{\prime} \alpha\right]$

The excess pore-pressure is derivable at $z=z_{l}$, indicating the seepage flow velocity is continuous herein. Submitting Eq. (5) into Eq. (9b), the liquefied soil depth $\left(z_{l}\right)$ can thereby be obtained as

$z_{l}=\frac{-p_{0} \cos (\lambda x+\omega t)}{\gamma^{\prime}}-\frac{1}{\operatorname{Re}\left[\lambda(1-\alpha)+\lambda^{\prime} \alpha\right]}$

in which the operator "Re\{ $\}$ " means to take the real-part of the complex variable. Note: both " $\alpha$ " and " $\lambda$ "' in Eq. (10) are complex numbers in the 2-D solutions for wave-induced pore-pressure in the seabed (see
Appendix A). Referring to Eq. (10), the maximum value of the liquefied soil depth under wave troughs, i.e. $(\lambda x+\omega t)=N \pi(N=1,3,5, \cdots)$ can be expressed as

$z_{\mathrm{L}}=\frac{p_{0}}{\gamma^{\prime}}-\frac{1}{\operatorname{Re}\left[\lambda(1-\alpha)+\lambda^{\prime} \alpha\right]}$

With the above revision on the liquefaction criterion (Eq. (3a,b)) and the corresponding modification on the wave-induced pore-pressure distribution (Eqs. (8a) and (8b)), the vertical distribution of the excess porepressure difference $\left(p-P_{\mathrm{b}}\right)$ in the seabed with instantaneously-liquefied layer under wave troughs can be determined (see Fig. 2).

For the comparison purpose, the vertical distribution of initial overburden effective stress $\sigma_{z 0}^{\prime}\left(=\gamma^{\prime} z\right)$ in the homogeneous sandy seabed is also presented in Fig. 2. The analytical results are based on the same waves and soil conditions as in the aforementioned case study (Section 2.1). For the two typical elements (i.e. element-2' and 3 ' in Fig. 2, in comparison with element-2 and 3 in Fig. 1) at the same depths, the elememt- $2^{\prime}$ is satisfied locally by the force balance $\left(j_{\mathrm{z}}-\gamma^{\prime}=0\right)$. After such modification on pore-pressure distribution, the force balance in the element scale can be satisfied for arbitrary locations between the seabed surface and the maximum liquefied soil depth $\left(0 \leq z \leq z_{\mathrm{L}}\right)$. At the same time, for an arbitrary location underneath the instantaneously-liquefied layer, i.e. $z>z_{\mathrm{L}}$ (e.g., element- $3^{\prime}$ ), a downward resultant force exists $\left(-j_{z}+\gamma^{\prime}>0\right)$ and thus the soil is in the unliquefied state.

The liquefied soil depth can be determined uniquely by Eq. (11) (e.g., $z_{\mathrm{L}}=0.54 \mathrm{~m}$ in the case study, see Fig. 2), which is in between the two values evaluated by the iteration calculation method with the existing two criteria $\left(z_{\mathrm{s}}=0.45 \mathrm{~m}, z_{\mathrm{p}}=0.93 \mathrm{~m}\right.$, respectively, see Fig. 1 ).

The present two-dimensional (2-D) solution for the instantaneouslyliquefied soil depth is compared with the previous one-dimensional (1D) approximation by Qi and Gao (2015). Fig. 3 gives the comparison of the variations of $z_{\mathrm{L}}$ with $L / h$ between the 1-D and the present 2-D solutions. It is indicated that, the values of $z_{\mathrm{L}}$ evaluated with the present 2-D approximation are always smaller than those with the 1-D approximation. With the increase of the non-dimensional wave length $L / h$ (normalized by water depth $h$ ), the relative divergence $\delta$ (the difference between 1-D and 2-D results divided by the 2-D result) decreases gradually from 0.17 to 0.08 , indicating the 2 -D effect should be taken into account, especially for the cases of short wave length (e.g., $L / h<6.0$, see Fig. 3).
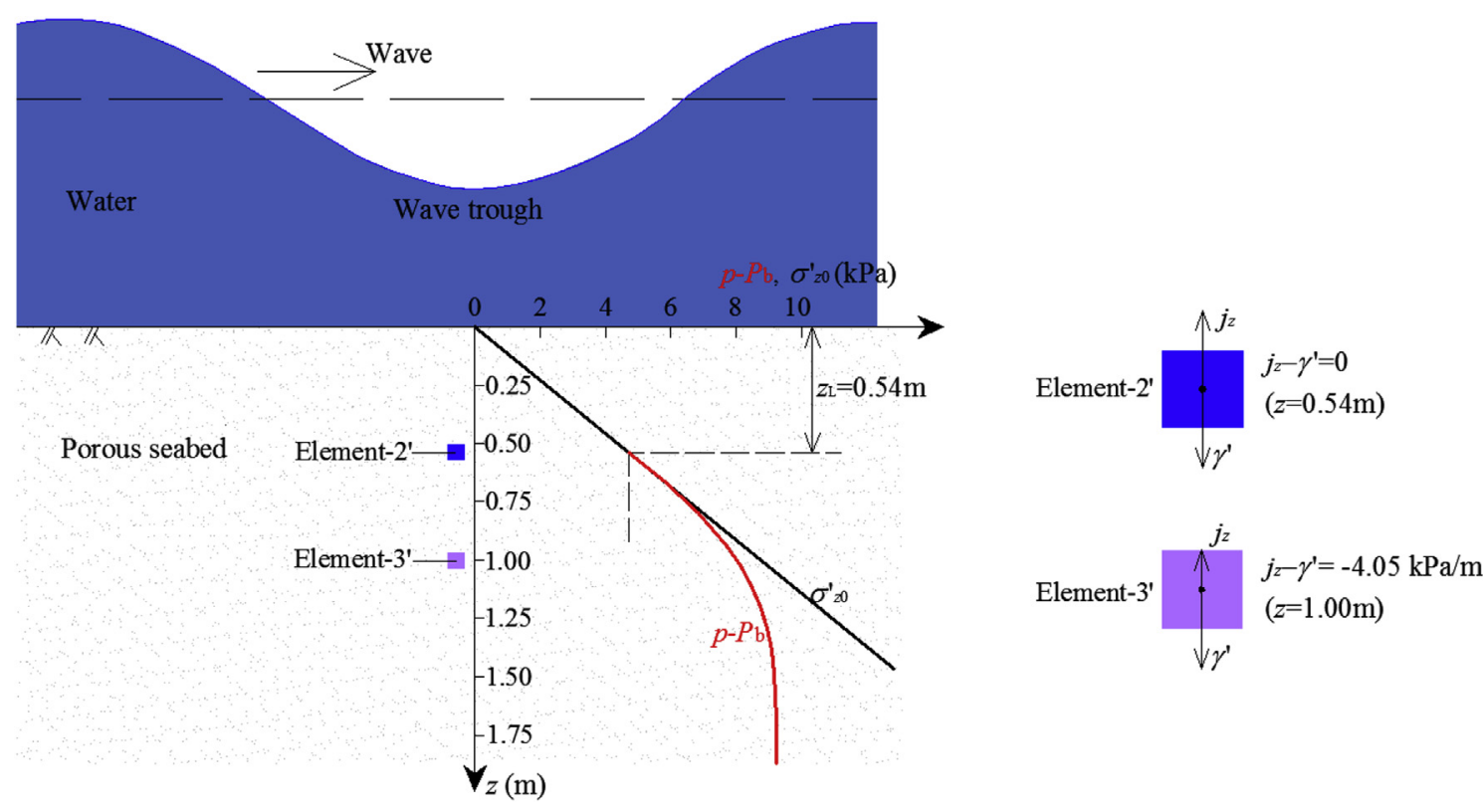

Fig. 2. The revised vertical distributions of $\left(p-P_{\mathrm{b}}\right), \sigma_{z 0}^{\prime}$, and the corresponding liquefied soil depth under wave troughs according to Eqs. (8a) and (8b). 


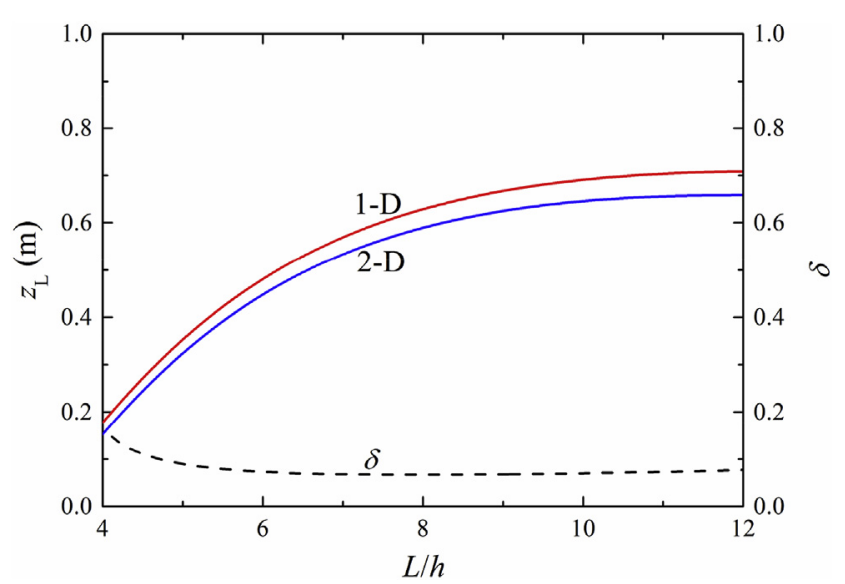

Fig. 3. Comparison of the variations of $z_{\mathrm{L}}$ with $L / h$ between the present 2-D solution and the 1-D approximation.

\subsubsection{Excess pore-pressure ratio}

Based on the analytical solutions in Section 2.2.1, the transient excess pore-pressure and the corresponding effective stress can be evaluated. Fig. 4 illustrates the vertical distributions of the 2-D wave induced porepressure $(p)$, the excess pore-pressure difference $\left(p-P_{\mathrm{b}}\right)$, the excess porepressure gradient $(d p / d z)$, the initial overburden effective stress $\left(\sigma_{\mathrm{z} 0}^{\prime}\right)$ and the transient vertical effective stress $\left(\sigma_{\mathrm{z}}^{\prime}\right)$ under wave troughs. Note that the wave parameters and soil properties are the same as those in the case study in Section 2.1. The transient vertical effective stress $\sigma_{z}^{\prime}$ has the following relationship with $\sigma_{\mathrm{z} 0}^{\prime}$ and $\left(p-P_{\mathrm{b}}\right)$ :

$\sigma_{z}^{\prime}=\sigma_{\mathrm{z} 0}^{\prime}-\left(p-P_{\mathrm{b}}\right)$

As shown in Fig. 4, the value of $\sigma_{\mathrm{z}}^{\prime}$ keeps as nil in the instantaneouslyliquefied layer $\left(0 \leq z \leq z_{\mathrm{L}}\right)$. With further increase of soil location into the underlying unliquefied sand, the seepage force decreases gradually to zero (e.g., at $z \lambda=0.15, \mathrm{~d} p / \mathrm{d} z \rightarrow 0$ ); at the same time, $\sigma_{\mathrm{z}}^{\prime}$ increases from zero and gradually approaches to $\sigma_{\mathrm{z} 0}^{\prime}+P_{\mathrm{b}}$ in deeper locations (e.g. at $z \lambda$ $=0.5, \sigma_{\mathrm{z}}^{\prime} / \sigma_{\mathrm{z} 0}^{\prime} \approx 0.83$, see Fig. 4). It should be noticed that, underneath the liquefied layer, there exists a remarkably deep layer (comparable to the value of $z_{\mathrm{L}}$ ) in the state of very low overburden effective stress.

To quantitatively evaluate the instantaneous liquefaction degree, an excess pore-pressure ratio $R$ is proposed for the given influential depth $z_{R}$ :

$R=\frac{p(z)-P_{\mathrm{b}}}{\sigma_{z 0}^{\prime}(z)} \quad\left(\right.$ at $\left.z=z_{\mathrm{R}}\right)$

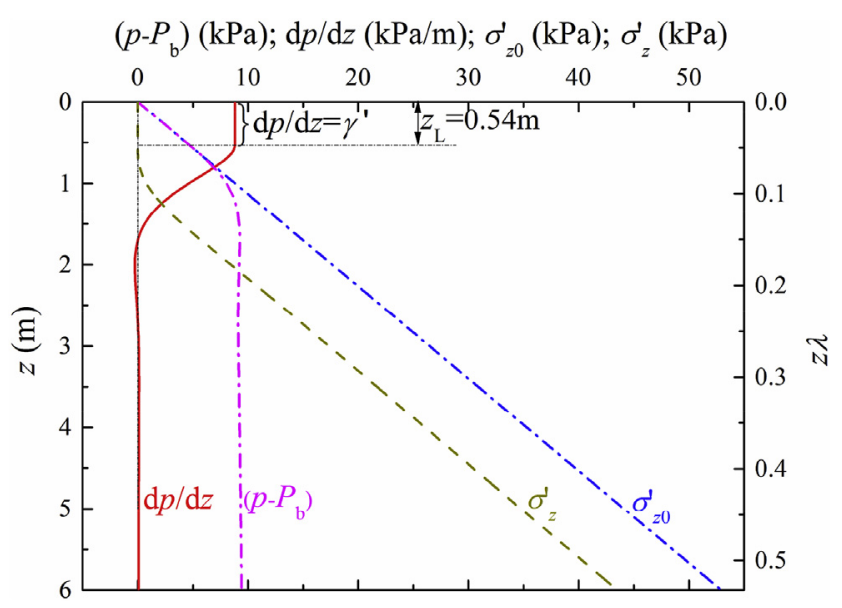

Fig. 4. Vertical distributions of $\left(p-P_{\mathrm{b}}\right), d p / d z, \quad \sigma_{\mathrm{z} 0}^{\prime}$ and $\sigma_{\mathrm{z}}^{\prime}$ under wave troughs. in which, the wave-induced pore-pressure $p(z)$ can be calculated with Eqs. (8a) and ( $8 \mathrm{~b}) ; \sigma_{z 0}^{\prime}(\boldsymbol{z})=\gamma^{\prime} z$ is the initial overburden effective stress in a homogenous sandy seabed. For each given value of $R$, the corresponding influential depth $z_{\mathrm{R}}$ can be obtained. In the fully liquefied layer $\left(0 \leq z \leq z_{\mathrm{L}}\right), R=1.0$ and $z_{\mathrm{R}}=z_{\mathrm{L}} ;$ and below fully liquefied layer $\left(z=z_{\mathrm{R}}>\right.$ $z_{\mathrm{L}}$ ), the influential depth $z_{\mathrm{R}}$ would be in the range of $0<R<1.0$. The excess pore-pressure ratio and its influential depth will be investigated in the parametric study (see Section 4).

\section{Comparisons with existing offshore field trials and numerical simulations: verifications}

\subsection{Comparison with the field observations by Mory et al. (2007)}

To substantially advance the design of foundations for coastal structures with regards to soil liquefaction, the European Union supported a three-year (2001-2004) research project on "Liquefaction around Marine Structures (LIMAS)" (Sumer, 2006). In the LIMAS project, a series of field trials on wave-induced instantaneous liquefaction were carried out at Capbreton on the Atlantic coast in southwest France in the year 2003 (Mory et al., 2007). In this section, their results of field trials will be compared with the present analytical solution for the purpose of verification.

As described by Mory et al. (2007), the sand on the beach is homogeneous, possessing mean particle size $d_{50}=0.35 \mathrm{~mm}$ (with $d_{10}=0.22 \mathrm{~mm}$ and $d_{90}=0.50 \mathrm{~mm}$ ). The main soil parameters are as follow: coefficient of permeability $k_{\mathrm{s}}=2 \times 10^{-4} \mathrm{~m} / \mathrm{s}$, shear modulus $G=20.0 \mathrm{MPa}$, Poisson ratio $\nu=0.33$ and saturation degree $S_{\mathrm{r}}=0.98$. The lower value of the density of soil particles was estimated as $\rho_{\mathrm{s}}=$ $2.60 \times 10^{3} \mathrm{~kg} / \mathrm{m}^{3}\left(G_{\mathrm{s}}=2.60\right)$ and the porosity $n=0.5$, whereas higher value of $\rho_{\mathrm{s}}=2.75 \times 10^{3} \mathrm{~kg} / \mathrm{m}^{3}$ and $n=0.4$. Thus, the buoyant unit weight of the sand would be in the range of $\gamma^{\prime}\left(=\left(G_{\mathrm{s}}-1\right)(1-n) \gamma_{\mathrm{w}}\right)=(8.0-10.5)$ $\mathrm{kN} / \mathrm{m}^{3}$.

In their offshore field experiments, five Druck PDCR 4030 pressure sensors (full range of $70 \mathrm{kPa}$ with a precision of $0.08 \%$ ) were used for the measurement of pressure or excess pore-pressure induced by waves. As illustrated in Fig. 5(a), the sensor $p_{2}$ was located at the seabed mudline; the three lower sensors $p_{3}, p_{4}$ and $p_{5}$ were inside the soil; the top sensor $p_{1}$ was in the water layer. The distance between the two neighboring sensors is $\Delta z=0.3 \mathrm{~m}$. For the three instantaneous liquefaction events, at the record time $5506 \mathrm{~s}, 5516 \mathrm{~s}$, and $5526 \mathrm{~s}$ (when the wave troughs passing over the sensors), the values of the maximum excess pore-pressure difference $\Delta p_{\mathrm{m}}$ are $2.8 \mathrm{kPa}, 3.5 \mathrm{kPa}$ and $3.5 \mathrm{kPa}$, respectively (see Fig. 5(a)). Note that the original data of pressure difference between $p_{2}$ and $p_{3}$ in the Figs. 11 and 12 of Mory et al. (2007) were the absolute pore-pressure difference (denoted as " $\Delta p_{3.2}$ "), which is the sum of the maximum excess pore-pressure difference $\Delta p_{\mathrm{m}}$ and the hydrostatic pressure difference of $\Delta z=0.3 \mathrm{~m}$ (i.e. $\Delta p_{3.2}=\Delta p_{\mathrm{m}}+3.0 \mathrm{kPa}$ ).

During the $2.5 \mathrm{~h}$ of a tidal cycle, 47 instantaneous liquefaction events were observed successively (see Fig. 5(b) and (c)). As shown in Fig. 5(b), even though the values of wave height $(H)$ preceding each of 47 liquefaction events seem quite scattering (but beyond the critical wave height inducing liquefaction), the maximum excess pore-pressure difference $\Delta p_{\mathrm{m}}$ approaches a threshold value (see $\Delta p_{\mathrm{m}} \approx 3.0 \mathrm{kPa}$, the circle dots in Fig. 5(b)). Such observations clearly indicate that, after occurrence of instantaneous liquefaction, a further increase of wave height could not induce higher excess pore-pressure difference in the liquefied soil layer.

Based on the above field trials' results for maximum excess porepressure difference $\Delta p_{\mathrm{m}}$ (see Fig. 5(b)), the vertical gradients $\left(\Delta p_{\mathrm{m}} / \Delta z\right)$ measured by the two sensors $p_{2}$ and $p_{3}$ (with $\Delta z=0.3 \mathrm{~m}$ ) in the liquefied layer can be further obtained, as shown in Fig. 6 . The evaluated values of buoyant unit weight of the in-situ sand are also provided in this figure: maximum value $\gamma_{\text {max }}^{\prime}=10.5 \mathrm{kN} / \mathrm{m}^{3}$, minimum value $\gamma_{\text {min }}^{\prime}=8.0 \mathrm{kN} / \mathrm{m}^{3}$, and averaged value $\gamma_{\text {average }}^{\prime}=9.25 \mathrm{kN} / \mathrm{m}^{3}$. It is found that the values of $\Delta p_{\mathrm{m}} / \Delta z$ precisely fall into the evaluated range of buoyant unit weight of 


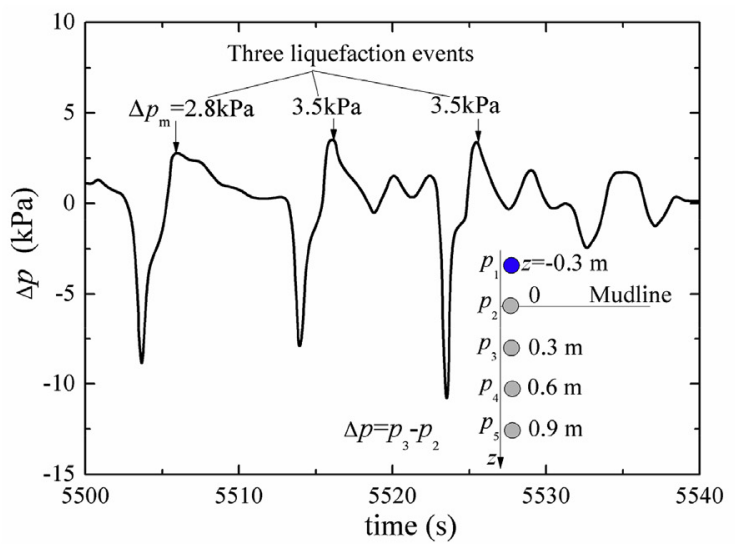

(a)

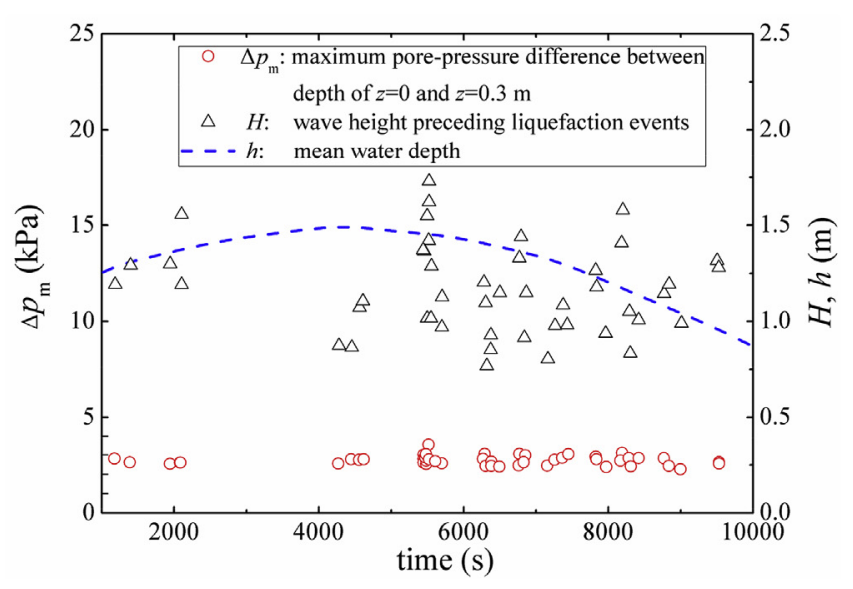

(b)

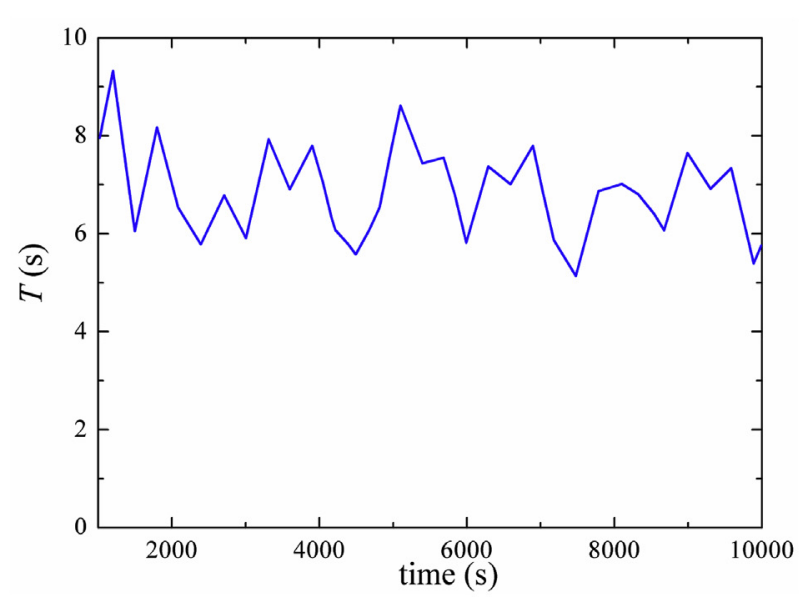

(c)

Fig. 5. (a) A typical time series of $\Delta p$ recorded by the two sensors $p_{2}$ and $p_{3}$; (b) the recorded $\Delta p_{\mathrm{m}}, h$ and $H$ preceding each of 47 instantaneous liquefaction events; and (c) variations of $T$ during $2.5 \mathrm{~h}$ of a tidal cycle (Reproduced from Mory et al. (2007)).

the in-situ sand $\gamma^{\prime}=9.25 \pm 1.25 \mathrm{kN} / \mathrm{m}^{3}$, i.e. $\Delta p_{\mathrm{m}} / \Delta z \approx \gamma^{\prime}$, which well coincides with the present criterion for instantaneous liquefaction of the non-cohesive seabed (Eq. (3a,b)). That is, the buoyant unit weight of the soil $\left(\gamma^{\prime}\right)$ would be balanced by the upward seepage force $\left(-\Delta p_{\mathrm{m}} / \Delta z\right)$ in the liquefied layer (also see Fig. 3).

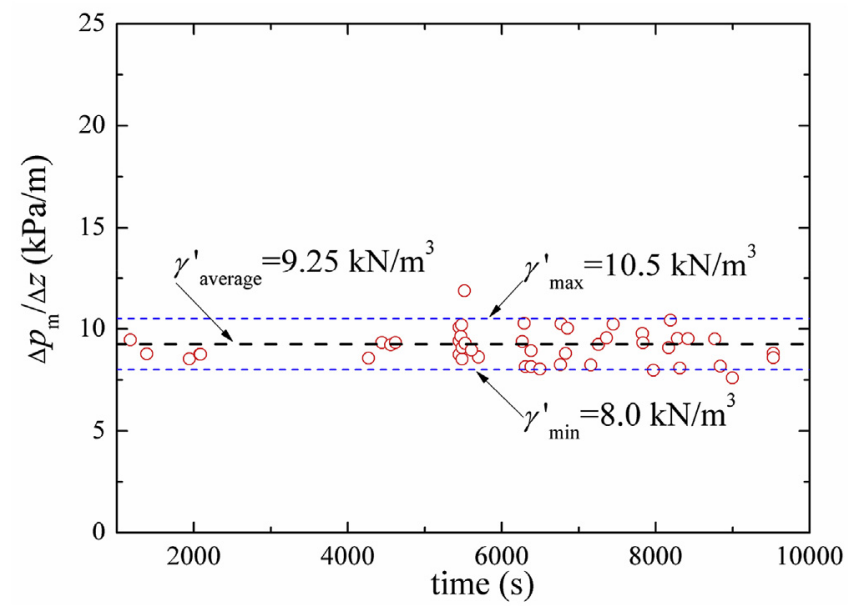

Fig. 6. Comparison between $\gamma^{\prime}$ and $\Delta p_{\mathrm{m}} / \Delta z$ for 47 instantaneous liquefaction events observed by Mory et al. (2007).

Given the soil properties of the in-situ sands, i.e. $k_{\mathrm{s}}=2 \times 10^{-4} \mathrm{~m} / \mathrm{s}$, $G=20.0 \mathrm{MPa}, \nu=0.33, S_{\mathrm{r}}=0.98, n=0.45$ (averaged), $\gamma^{\prime}=9.25 \mathrm{kN} / \mathrm{m}^{3}$ (averaged), and the wave parameters of the aforementioned 47 instantaneous liquefaction events (time variations of $h, T$ and $H$ are shown in Fig. 5(b) and (c)), the maximum liquefaction depth $z_{\mathrm{L}}$ can be calculated with the present analytical solution (see Section 2.2), as shown in Fig. 7. The calculated results of both $z_{\mathrm{L}}(R=1.0)$ and $z_{\mathrm{R}}$ for $R=0.97$ are given in Fig. 7(a). The parameters $R$ and $z_{R}$ are the transient excess pore-pressure ratio (liquefaction degree) and the corresponding influential depth, respectively; and their definitions are detailed in Section 4.

Note that in the above liquefaction events of offshore field trials, the values of $\Delta p_{\mathrm{m}}$ were measured with the two sensors ( $p_{2}$ and $p_{3}$ ) with $\Delta z=$ $0.3 \mathrm{~m}$ from the mudline. As such, the measured values of liquefaction depth in the field observations would be larger than the location of the sensor $p_{3}$, i.e. $z_{\mathrm{L}} \geq 0.3 \mathrm{~m}$. Fig. 7(a) indicates that the predictions of $z_{\mathrm{L}}$ with the present analytical solution match well with the results for the observed 47 liquefaction events. As stated in Section 2.2, underneath the fully liquefied layer, there exists a remarkably deep layer in the state of very low overburden effective stress $(R \sim 1.0)$. Fig. $7(\mathrm{~b})$ gives the vertical distributions of $d p / d z,\left(p-P_{\mathrm{b}}\right), \sigma_{\mathrm{z}}^{\prime}$ and $\sigma_{\mathrm{z} 0}^{\prime}$ for the selected liquefaction event $(h=1.4 \mathrm{~m}, T=7.5 \mathrm{~s}$ and $H=0.75 \mathrm{~m}$; marked with solid triangle/ circle in Fig. 7(a)). So, if choosing $R=0.97$, the predicted depth $z_{\mathrm{R}}$ (red circles in Fig. 7(a)) would be totally larger than $0.3 \mathrm{~m}$.

\subsection{Verification with multi-scale DEM-PFV simulations by Scholtès et al. (2015)}

Another evidence for the discrepancy of existing criteria on instantaneous liquefaction was presented by Scholtès et al. (2015), using the discrete element method (DEM) coupled with a pore-scale finite volume (PFV) scheme capable of describing compressible seepage flow at the pore-scale (or particles scale). The multi-scale DEM-PFV model consists of a column of soil particles resting on a rigid impermeable bottom and subjected to a pressure variation on its surface, and meanwhile the periodic boundary conditions were used (see Fig. 8(a)), for simulating macroscopic mechanical behaviors of one-dimensional (1-D) wave-seabed interaction.

Typical numerical results for variations of vertical effective stress ratio $\sigma_{\mathrm{z}}^{\prime} / \sigma_{\mathrm{z} 0}^{\prime}$ with time at different dimensionless depths inside the seabed $z / h_{\mathrm{s}}$ are given in Fig. 8(b) $\left(h_{\mathrm{s}}\right.$ denotes the height of simulated soil column), under the conditions of 1-D wave parameters $(T=1.0 \mathrm{~s}$, $\left.p_{0}=5 \mathrm{kPa}\right)$ and soil properties $\left(k_{\mathrm{s}}=1.5 \times 10^{-3} \mathrm{~m} / \mathrm{s}, \quad E=3.2 \mathrm{MPa}\right.$, $\left.n=0.42, \nu=0.215, S_{\mathrm{r}}=0.98\right)$. As stated by Scholtès et al. (2015), the effective stress computed in their numerical model remains always strictly positive although it approaches zero, e.g., $t=0.5-0.8$ s (under 


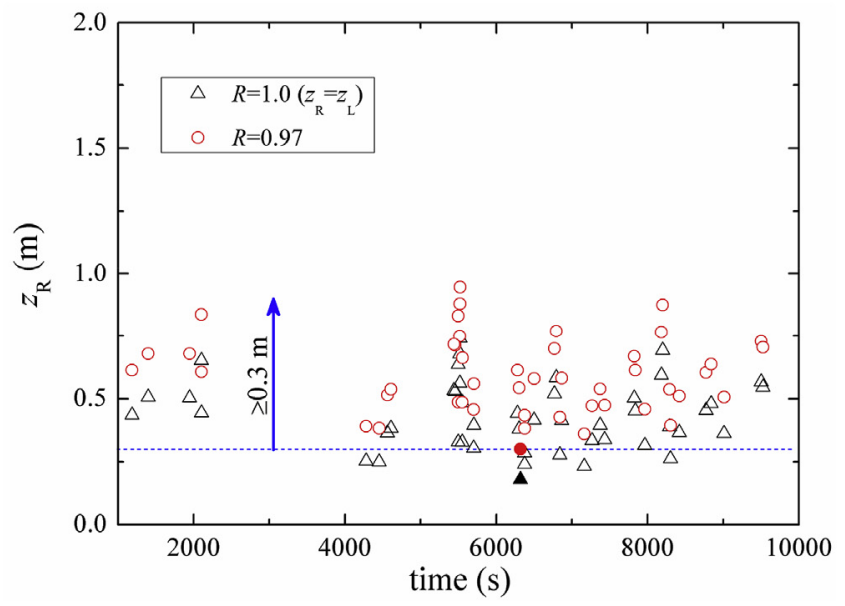

(a)

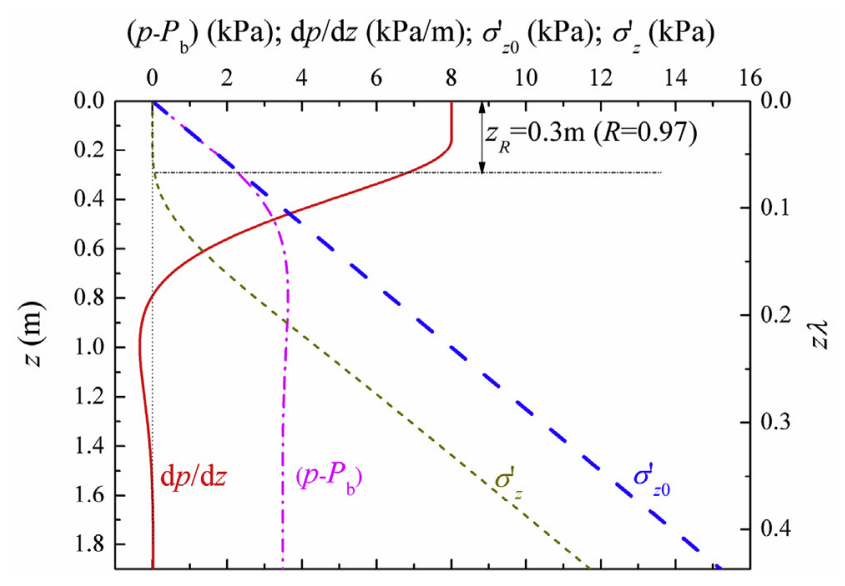

(b)

Fig. 7. Predictions with the present solution for the observed 47 liquefaction events: (a) maximum liquefied soil depth; (b) vertical distributions of $d p / d z$, $\left(p-P_{\mathrm{b}}\right), \sigma_{\mathrm{z}}^{\prime}$ and $\sigma_{\mathrm{z} 0}^{\prime}$ for the selected liquefaction event (marked with solid triangle/circle in Fig. 7(a)).

troughs) at $z / h_{\mathrm{s}}=0.1,0.3$, see Fig. $\left.8(\mathrm{~b})\right)$. That is, no tensile effective stress can be generated in an instantaneously-liquefied granular medium (sandy seabed). The analytical solution from Nago and Maeno (1987), which is one-dimensional approximation of the Yamamoto solution, was also shown in Fig. 8(b). As opposed to the DEM-PFV simulations, the existing analytical solution (without pore-pressure modification after occurrence of liquefaction) for the effective stress distribution had to be arbitrarily dammed up at $\sigma_{\mathrm{z}}^{\prime} / \sigma_{\mathrm{z} 0}^{\prime}=0$ (see the bold dashed line in grey color in Fig. 8(b)), which could not properly reflect the wave-induced pore-pressure transmission where sand particles are suspended in the liquefied layer (Scholtès et al., 2015). It was therefore motivated to further revise existing criteria on instantaneous liquefaction and the corresponding wave-induced pore-pressure distribution in the seabed with instantaneously-liquefied layer, which is described in Section 2.2.

\section{Parametric study}

In the following parametric study on the influential depth, three typical values of excess pore-pressure ratio are chosen, i.e. $R=1.0,0.9$ and 0.5 . The effects of soil properties (including degree of saturation and coefficient of permeability) and wave parameters (including wave height and water depth) on the corresponding influential depth $z_{\mathrm{R}}$ will be examined, respectively. The input data for the seabed and waves

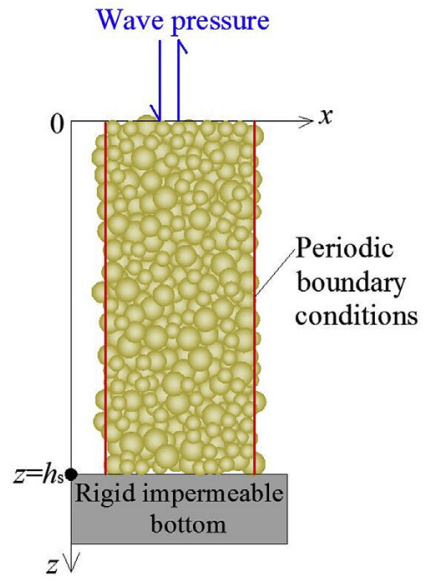

(a)

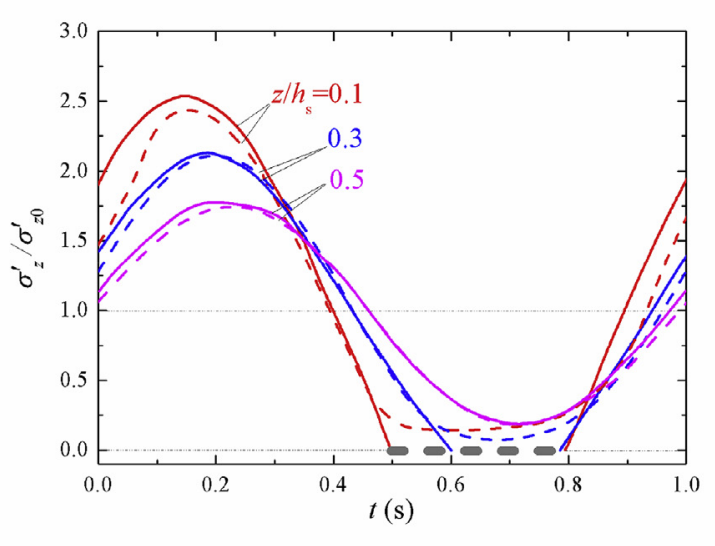

(b)

Fig. 8. (a) Illustration of numerical geometry for the DEM-PFV model (adapted from Scholtès et al., 2015); (b) variations of $\sigma_{\mathrm{z}}^{\prime} / \sigma_{\mathrm{z} 0}^{\prime}$ with time at different values of $z / h_{s}$. Dashed lines: DEM-PFV model predictions; Solid lines: 1-D solutions from Nago and Maeno (1987).

are listed in Table 1.

\subsection{Effects of seabed properties}

The degree of saturation $\left(S_{\mathrm{r}}\right)$ and the coefficient of permeability $\left(k_{\mathrm{s}}\right)$ for the sand are key influencing factors for the transmission of porepressure inside the seabed. As indicated in previous studies (Tørum, 2007; Michallet et al., 2009), the air content of up to $3-5 \%$ $\left(S_{\mathrm{r}}=0.97-0.95\right)$ may typically be entrapped in the pores of the sandy seabed, which would change the apparent bulk modulus of pore-fluid $K^{\prime}$ and further affect the pore-pressure transmission behavior. The apparent bulk modulus of pore-fluid $K^{\prime}$ is calculated by $\frac{1}{K^{\prime}}=\frac{1}{K}+\frac{1-S_{\mathrm{r}}}{P_{0}}$, in which $K$ is the true bulk modulus of pure water $\left(K=1.9 \times 10^{9} \mathrm{~Pa}\right)$ and $P_{0}$ is the absolute hydrostatic pressure at the location in the seabed. With a small fraction of air in the water, say $S_{\mathrm{r}}=0.99$, the apparent bulk modulus of pore-fluid decreases by almost two orders of magnitude, i.e. $K^{\prime}=2 \times 10^{7} \mathrm{~N} / \mathrm{m}^{2}$.

As indicated by Eq. (A5) in Appendix A, the shape of the vertical distribution of wave-induced pore-pressure is mainly related to the two parameters ( $\alpha$ and $\lambda^{\prime}$ ) for the soil and the wave number $(\lambda)$. Based on the expressions for $\alpha$ and $\left(\lambda^{\prime}\right)^{2}$ by Eqs. (A6) and (A7), respectively, and by using dimensional analysis, two dimensionless forms for the soil 
Table 1

Input data for parametric study.

\begin{tabular}{lll}
\hline & Parameters & Values \\
\hline Seabed properties & Degree of saturation $S_{\mathrm{r}}$ & 0.98 (various in Section 4.1 ) \\
& Coefficient of permeability $k_{\mathrm{s}}(\mathrm{m} / \mathrm{s})$ & $1 \times 10^{-4}($ various in Section 4.1$)$ \\
& Elastic modulus $E(\mathrm{MPa})$ & 30.0 \\
& Porosity of soil $n$ & 0.45 \\
& Poisson ratio of soil $\nu$ & 0.30 \\
& Submerged unit weight of soil $\gamma^{\prime}\left(\mathrm{kN} / \mathrm{m}^{3}\right)$ & 8.0 \\
\hline Wave parameters & Water depth $h(\mathrm{~m})$ & 10.0 (various in Section 4.2$)$ \\
& Wave height $H(\mathrm{~m})$ & 3.0 (various in Section 4.2$)$ \\
\hline
\end{tabular}

parameters $K^{\prime}$ and $k_{\mathrm{s}}$ can be deduced as $G / K^{\prime}$ and $k_{\mathrm{s}} G / \gamma_{\mathrm{w}} g^{2} T^{3}$, respectively. Note that the non-dimensional parameters $n$ and $\nu$ are kept unchanged in this parametric study. $G / K^{\prime}$ is the ratio of shear modulus of soil $G$ to the apparent bulk modulus of pore-fluid $K^{\prime}$, which essentially reflects the influence of saturation degree $S_{\mathrm{r}}$.

Fig. 9 gives the variations of the influential depth $z_{\mathrm{R}}$ and its nondimensional form $z_{\mathrm{R}} / H$ with $G / K^{\prime}$. As shown in Fig. 9, for a fixed value of $R$, the influential depth increases with increasing $G / K^{\prime}$. When $G / K^{\prime} \leq$ 3.0 (i.e. $S_{\mathrm{r}} \geq 0.971$ ), the influential depth decreases dramatically with decreasing $G / K^{\prime}$. Note that when $G / K^{\prime} \leq 0.71\left(S_{\mathrm{r}} \geq 0.993\right)$, the instantaneous liquefaction will not happen, indicating the downward attenuation of the wave-induced pore-pressure is effectively alleviated with increasing the bulk modulus of pore-fluid. Meanwhile, the decrease of $R$ would bring the corresponding influential depth $z_{\mathrm{R}}$ increase significantly. For a fixed value of $G / K^{\prime}$ (e.g. $G / K^{\prime}=10$ ), if the excess pore-pressure ratio decreases from $R=1.0$ to 0.5 , the influential depth would be increased by approximately 2.5 times.

The variation of influential depth $z_{\mathrm{R}}$ with the permeability coefficient $k_{\mathrm{S}}$ is shown in Fig. 10. Meanwhile, their corresponding non-dimensional parameters $z_{\mathrm{R}} / H$ and $k_{\mathrm{s}} G / \gamma_{\mathrm{w}} g^{2} T^{3}$ are also given in the right and the top axis for reference, respectively. As indicated in Fig. 10, the examined range of $k_{\mathrm{s}}$ covers three types of sands, i.e. fine, medium and coarse sands (see Das, 2008). It can be seen that $z_{\mathrm{R}}$ generally keeps decreasing with decreasing $k_{\mathrm{s}}$. For the case of $R=0.9$, the decrease of $z_{\mathrm{R}}$ mainly emerges in the range of $k_{\mathrm{s}}>10^{-4} \mathrm{~m} / \mathrm{s}$ (coarse sand). For the case of $R=0.5$, the decrease of $z_{\mathrm{R}}$ is mild for the whole examined range of $k_{s}$. With decreasing value of $R$, the corresponding influential depth $z_{\mathrm{R}}$ increases significantly. The influential depth for $R=0.5$ is generally over twice of that for $R=1.0\left(z_{\mathrm{L}}\right)$.

\subsection{Effects of wave parameters}

In order to investigate the effects of wave parameters on the influential depth, the values of wave height the water depth are varied indi-

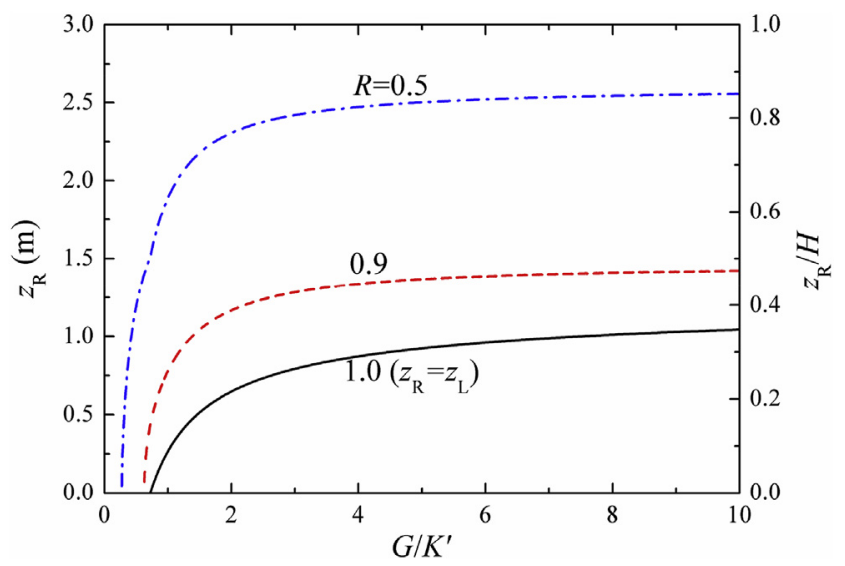

Fig. 9. Effects of saturation degree of soil: Variations of $z_{\mathrm{R}}$ with $G / K^{\prime}$. vidually, while the other parameters remaining as constants (see Table 1). Fig. 11(a) and (b) show the variations of influential depth $z_{\mathrm{R}}$ with wave height $H$, and those of non-dimensional $z_{\mathrm{R}} / H$ with $H / h$, respectively. Fig. 11(a) and (b) indicate that only when the wave height is larger than a threshold value (e.g., $H / h \approx 0.15$ ), the sandy seabed can be fully instantaneously-liquefied. The liquefied soil depth $z_{R}$ seems increasing approximately linearly with the increase of wave height $H$ (see Fig. 11(a)); Nevertheless, the non-dimensional relationships in Fig. 11(b) further indicate that $z_{\mathrm{R}} / H$ increases gradually with the increase of $H / h$ initially, but approaches to a constant value (e.g., $z_{\mathrm{R}} / H \approx 0.32$, at $H$ / $h=0.6$ ) under the examined soil conditions. Note that, in the examination for wave height effects, the wave breaking criterion should be taken into account, which can be described by $\frac{H_{\mathrm{b}}}{L_{\mathrm{b}}} \approx 0.142 \tanh \frac{2 \pi h_{\mathrm{b}}}{L_{\mathrm{b}}}$ (see Liu et al., 2011), where $H_{\mathrm{b}}, L_{\mathrm{b}}$ and $h_{\mathrm{b}}$ denote wave height, wave length and water depth as wave breaking occurs, respectively.

Fig. 12 gives the variation of influential depth $z_{\mathrm{R}}$ with water depth $h$. The scales of non-dimensional influential depth $z_{\mathrm{R}} / H$ and nondimensional water depth $h / g T^{2}$ are also shown in the right and the top axis, respectively. The non-dimensional parameter $h / g T^{2}$ reflects the relative quantity of water depth to wave length. As shown in Fig. 12, the influential depth decreases with increasing water depth for a certain value of $R$. The influential depth can be nearly tripled while the value of $R$ decreases from 1.0 to 0.5 .

In addition, as shown in Fig. 9-12 of the parametric study, the values of maximum liquefied soil depth under the examined conditions are generally less than half of the wave height, i.e. $z_{\mathrm{L}} / H<0.5$; but the values of influential depth for $R=0.5$ can be up to the magnitude of the loading wave height, i.e. $z_{\mathrm{R}(\mathrm{R}=0.5)} / H \sim 1.0$. Even under some conditions without

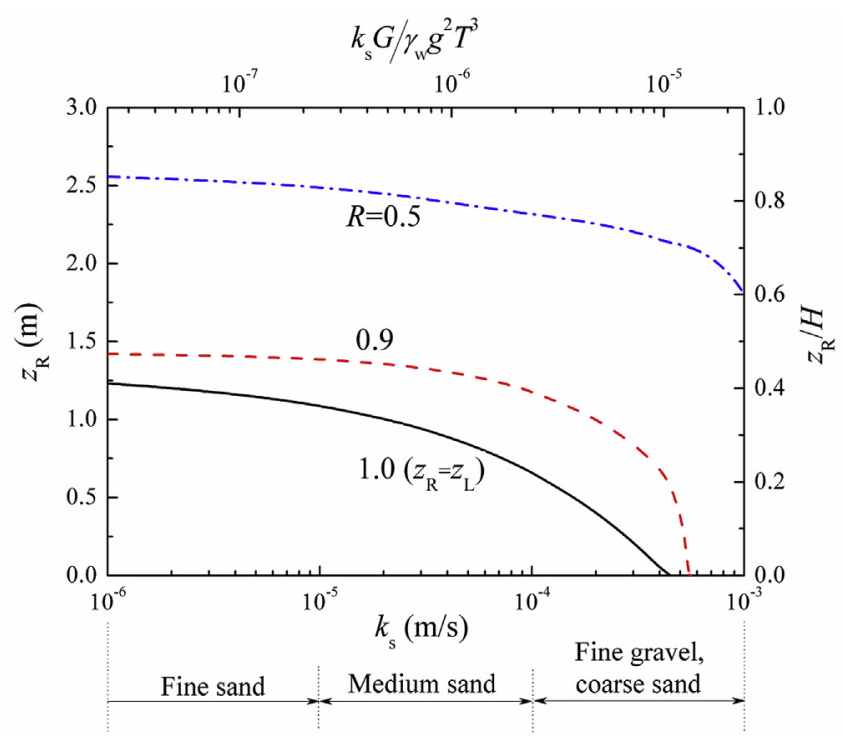

Fig. 10. Effects of permeability coefficient of soil: variations of $z_{\mathrm{R}}$ with $k_{\mathrm{s}}$ or $k_{\mathrm{s}} G / \gamma_{\mathrm{w}} g^{2} T^{3}$. 


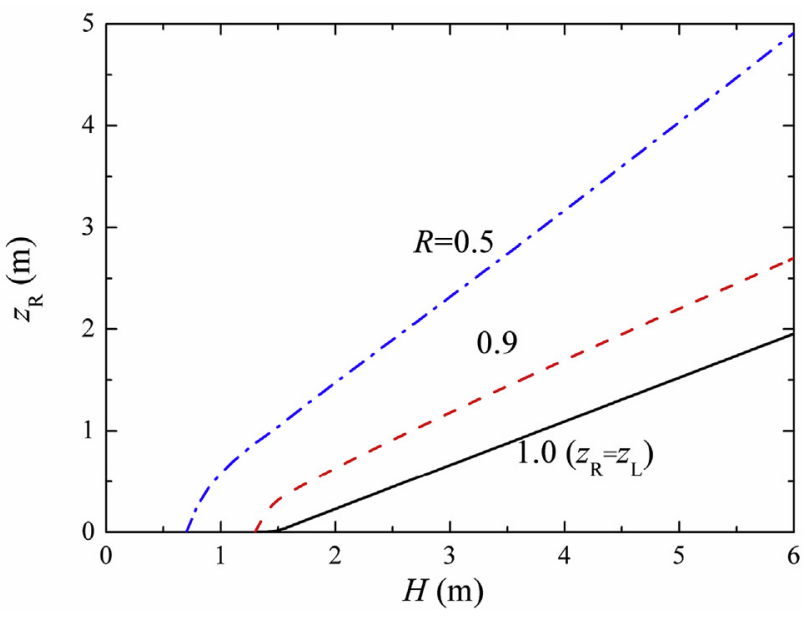

(a)

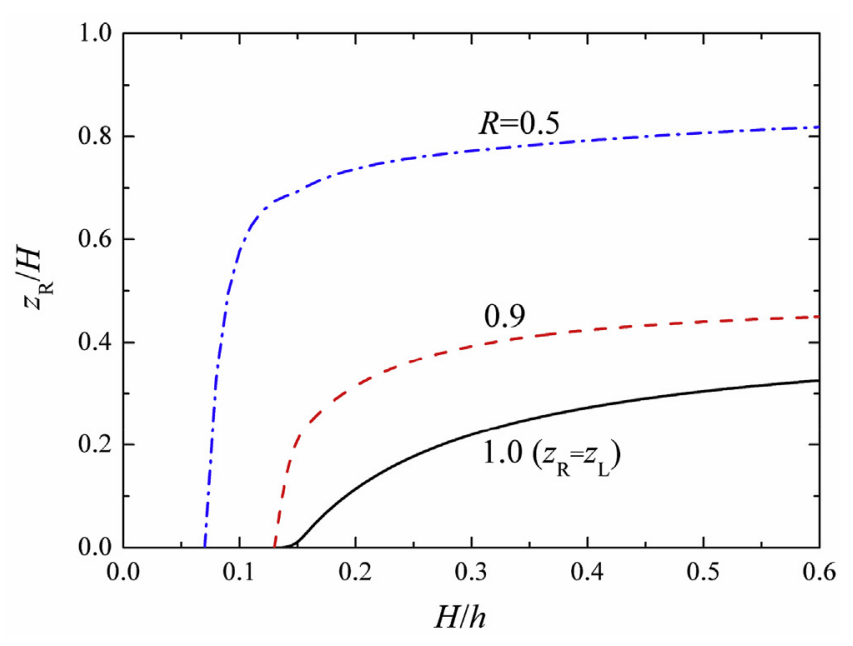

(b)

Fig. 11. Effects of wave height: (a) variations of $z_{\mathrm{R}}$ with $H$; (b) variations of $z_{\mathrm{R}} / H$ with $H / h$.

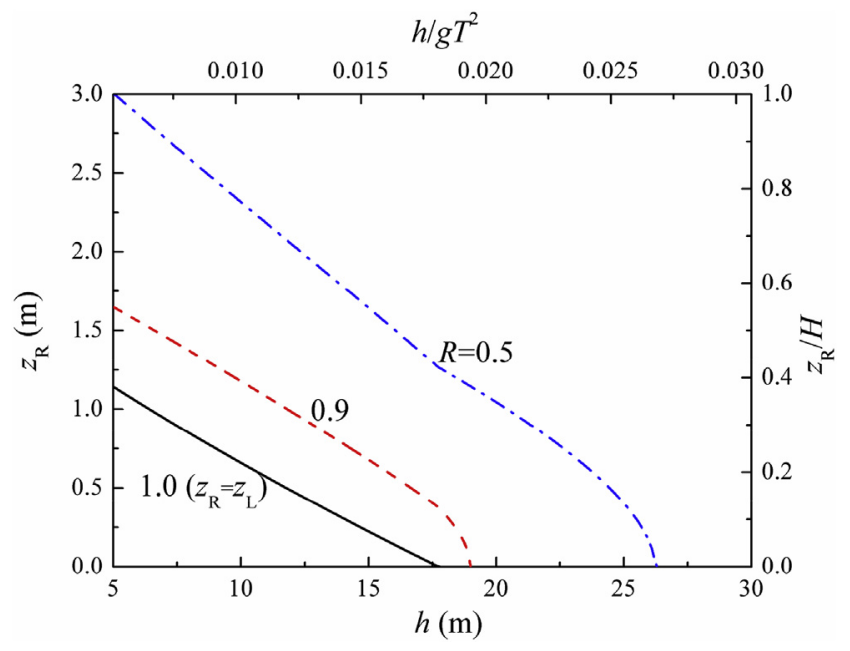

Fig. 12. Effects of water depth: variations of influential depth with water depth. fully liquefied layer $\left(z_{\mathrm{L}}=0\right)$, the influential depth for $R=0.5$ could be over half of the wave height $\left(z_{\mathrm{R}} / H>0.5\right)$. That is, the influential depth of a non-cohesive seabed under waves increases significantly with reducing the level of excess pore-pressure ratio, which may have much influence on the stability design for submarine structures.

\section{Conclusions}

In the wave-dominated coastal locations or the surf zones, instantaneous liquefaction of a sandy seabed can occur under severe storms. The wave-induced pore-pressure distribution in the non-cohesive seabed with an instantaneously-liquefied layer is investigated analytically.

Based on the solution to Biot's consolidation equations for porous media and the assumption that the excess pore-pressure cannot exceed the initial vertical effective stress, the expressions of instantaneouslyliquefied soil depth are derived and verified with the existing offshore field observations and multi-scale numerical simulations.

Analytical investigation indicates that in the instantaneouslyliquefied layer, the buoyant weight of soil is essentially balanced locally by upward seepage force in a quasi-static state. Underneath the fully liquefied layer, the effective stress can even be reduced remarkably into deeper locations due to the slow decrease of vertical pore-pressure gradients in the vicinity of the liquefaction layer. An excess porepressure ratio $(R)$ is thereby proposed to quantitatively evaluate the instantaneous liquefaction degree and its corresponding influential depth.

Parametric studies indicate that, for a certain excess pore-pressure ratio, the influential depth decreases with increasing saturation degree, permeability of the sand, but increases with increasing wave height. The influential depth increases significantly with reducing the excess porepressure ratio. The maximum value of the instantaneously-liquefied soil depth is generally smaller than half wave height. Nevertheless, the influential depth could increase significantly with reducing the threshold value of excess pore-pressure ratio. The reduction of effective stress in the seabed underneath the fully liquefied soil layer should also be taken into account when evaluating the stability of submarine structures.

\section{Acknowledgements}

This work was financially supported by the National Natural Science Foundation of China (Grant Nos. 11372319, 11602273), the Strategic PriorityResearch Program (Type-B) of CAS (Grant No. XDB22030000) and the Youth Innovation Promotion Association CAS.

\section{Appendix A. Analytical solution for the pore-pressure response of a poro-elastic bed to water waves}

An analytical solution for the pore-pressure response in a poro-elastic seabed with infinite thickness was obtained by Yamamoto et al. (1978), on the basis of three-dimensional consolidation theory of Biot (1940). The Yamamoto solution has been widely used for evaluating wave-seabed interactions. The derivation is briefly presented as follows.

The governing equations include the following three partial differential equations with three unknown variables, $p, u$ and $w$ :

$$
\begin{gathered}
\frac{k_{\mathrm{s}}}{\gamma_{\mathrm{w}}} \nabla^{2} p=\frac{n}{K^{\prime}} \frac{\partial p}{\partial t}+\frac{\partial \varepsilon}{\partial t} \\
G \nabla^{2} u+\frac{G}{1-2 \nu} \frac{\partial \varepsilon}{\partial x}=\frac{\partial p}{\partial x} \\
G \nabla^{2} w+\frac{G}{1-2 \nu} \frac{\partial \varepsilon}{\partial z}=\frac{\partial p}{\partial z}
\end{gathered}
$$

Eq. (A1.1) is derived by combining the continuity equation and 
Darcy's law, while Eqs. (A1.2) and (A1.3) are deduced from the equations of equilibrium incorporating the effective stress concept and Hooke's law. In Eqs. (A1.1), (A1.2) and (A1.3), $u$ is the $x$ component of soil displacement, $w$ is the $z$ component of soil displacement. $\varepsilon$ is the volume strain of the porous medium, under 2-D condition which can be expressed as $\varepsilon=\frac{\partial u}{\partial x}+\frac{\partial w}{\partial z}$. The effective stresses are related to the strains by Hooke's law as

$$
\begin{gathered}
\sigma_{x}^{\prime}=2 G\left(\frac{\partial u}{\partial x}+\frac{\nu}{1-2 \nu} \varepsilon\right) \\
\sigma_{z}^{\prime}=2 G\left(\frac{\partial w}{\partial x}+\frac{\nu}{1-2 \nu} \varepsilon\right) \\
\tau_{x z}=G\left(\frac{\partial u}{\partial z}+\frac{\partial w}{\partial x}\right)
\end{gathered}
$$

where $\sigma_{x}^{\prime}$ is the effective normal stress in the $x$ direction, $\sigma_{z}^{\prime}$ is the effective normal stress in the $z$ direction, and $\tau_{x z}$ is the shear stress in the $z$ direction on the plane perpendicular to the $x$ axis.

Three independent conditions per boundary are needed to solve the three simultaneous partial differential equations Eqs. (A1.1), (A1.2) and (A1.3). At the seabed surface, the boundary conditions are that vertical effective stress is zero, that the shear stress is negligibly small, and that the sinusoidal pressure fluctuation exists, i.e. at $z=0$ :

$$
\begin{gathered}
\sigma_{z}^{\prime}=2 G\left[\frac{\partial w}{\partial z}+\frac{\nu}{1-2 \nu}\left(\frac{\partial u}{\partial x}+\frac{\partial w}{\partial z}\right)\right]=0 \\
\tau_{x z}=G\left(\frac{\partial u}{\partial z}+\frac{\partial w}{\partial x}\right)=0 \\
\left.p_{\mathrm{b}} \equiv p\right|_{z=0}=p_{0} \cos (\lambda x+\omega t)
\end{gathered}
$$

The boundary conditions for a semi-infinite half plane may be given as

$$
u, w, p \rightarrow 0, \quad \text { as } \quad z \rightarrow \infty
$$

Harmonic solutions of $p$ can be derived by combining the three governing equations (Eqs. (A1.1) (A1.2) and (A1.3)), and the boundary conditions (Eqs. (A3) and (A4)), as follow

$$
p=P_{\mathrm{b}}\left\{(1-\alpha) \exp (-\lambda z)+\alpha \exp \left(-\lambda^{\prime} z\right)\right\}
$$

where

$$
\begin{gathered}
\alpha=\frac{i m \omega^{\prime \prime}}{-\lambda^{\prime \prime}+i(1+m) \omega^{\prime \prime}} \\
\left(\lambda^{\prime}\right)^{2}=\lambda^{2}+i \frac{\gamma_{\mathrm{w}}}{k_{\mathrm{s}}} \omega\left(\frac{n}{K^{\prime}}+\frac{1-2 \nu}{2(1-\nu) G}\right)
\end{gathered}
$$

$m=\frac{n}{K^{\prime}} \frac{G}{1-2 \nu}, \omega^{\prime \prime}=\beta\left(\omega^{\prime} / \lambda^{2}\right), \beta=\frac{1-\nu}{1-2 \nu}, \lambda^{\prime \prime}=\left(\lambda^{\prime}-\lambda\right) / \lambda, \omega^{\prime}=\omega / c, c=\frac{k_{s}}{\gamma_{\mathrm{w}}} /\left(\frac{n}{K^{\prime}}+\frac{1-2 \nu}{2(1-\nu) G}\right)$, and $i$ is the imaginary number.

For the soil is completely saturated and the pore-water does not contain gases, the value of $G / K^{\prime}$ approaches zero. As $G / K^{\prime} \rightarrow 0$, then $m \rightarrow 0$. For the limit, the following approximation for the pore-pressure distribution can be obtained from Eq. (A5):

$$
p=P_{\mathrm{b}} \exp (-\lambda z)
$$

When the stiffness of the soil becomes much larger than that of the pore-fluid, i.e. $G / K^{\prime} \rightarrow \infty$, then Eq. (A5) becomes

$$
p=P_{\mathrm{b}} \exp \left(-\lambda^{\prime} z\right)
$$

Since $\left|\lambda^{\prime}\right|>\lambda$ for this case, the pressure attenuates rapidly compared with Eq. (A8).

The actual pore-pressure response lies between the two aforementioned extreme cases and must be determined by the exact solution of Eq. (A5) based on the stiffness, permeability and the degree of saturation of the soil.

\section{Notation}

The following symbols are used in this paper:

$c \quad$ coefficient in Eq. (A5)

$d_{10} \quad$ effective diameter of sands

E soil elasticity modulus

$g \quad$ gravitational acceleration 
$G \quad$ shear modulus of the soil

$G_{\text {s }} \quad$ specific gravity of soil particles

$H \quad$ wave height

$H_{\mathrm{b}} \quad$ wave height as wave breaking occurs

$h \quad$ water depth

$h_{\mathrm{b}} \quad$ water depth as wave breaking occurs

$h_{\mathrm{s}} \quad$ height of simulated soil column

$i \quad$ imaginary number

$j_{\mathrm{z}} \quad$ seepage force acting on the soil skeleton

$K \quad$ true bulk modulus of water

$K^{\prime} \quad$ apparent bulk modulus of pore-fluid

$k_{\mathrm{s}} \quad$ coefficient of permeability

$L \quad$ wave length

$L_{\mathrm{b}} \quad$ wave length as wave breaking occurs

coefficient in Eq. (A5)

soil porosity

$P_{0} \quad$ absolute hydrostatic pressure

$P_{\mathrm{b}} \quad$ wave pressure at the seabed surface

$P^{\prime}{ }_{\mathrm{b}} \quad$ wave-induced pressure at the interface between the liquefied and unliquefied soil layers

wave-induced oscillatory pore-pressure in the soil

$p_{0} \quad$ amplitude of wave-induced pressure at the surface of the seabed

$R \quad$ excess pore-pressure ratio

$S_{\mathrm{r}} \quad$ degree of saturation

$T \quad$ wave period

$t$ time

soil depth calculated from the mudline

soil depth calculated from the interface between the liquefied and unliquefied soil layers

liquefaction depth based on the revised pore-pressure distribution

maximum liquefaction depth based on the revised pore-pressure distribution

liquefied soil depth based on criterion-II (Eq. (2)) by incorporating the conventional analytical solutions

influential depth corresponding to a certain value of the transient excess pore-pressure ratio

liquefied soil depth based on criterion-I (Eq. (1)) by incorporating the conventional analytical solutions

coefficient in Eq. (A5)

coefficient in Eq. (A5)

buoyant unit weight of soil

unit weight of water

wave number $(=2 \pi / L)$

coefficient in Eq. (A5)

coefficient in Eq. (A5)

Poisson ratio of soil

$\rho_{\mathrm{s}} \quad$ density of soil particles

$\rho_{w} \quad$ density of the water

$\sigma_{z}^{\prime} \quad$ vertical effective stress

$\sigma_{z 0}^{\prime} \quad$ initial vertical effective stress

$\omega^{\prime}$

angular frequency of the wave

coefficient in Eq. (A5)

$\omega^{\prime \prime} \quad$ coefficient in Eq. (A5)

$\Delta p \quad$ pore-pressure difference between two pore-pressure sensors

$\Delta p_{\max } \quad$ maximum pore-pressure difference between two pore-pressure sensors

\section{References}

Bear, J., 1972. Dynamics of Fluids in Porous Media. Courier Dover Publications, Dove. Cheng, H.-D., Liu, P.L.-F., 1986. Seepage force on a pipeline buried in a poroelastic seabed under wave loading. Appl. Ocean Res. 8 (1), 22-32.

Cheng, L., Sumer, B.M., Fredsöe, J., 2001. Solution of pore pressure build up due to progressive waves. Int. J. Numer. Anal. Meth. GeoMech. 25, 885-907.

Chowdhury, B., Dasari, G.R., Nogami, T., 2006. Laboratory study of liquefaction due to wave-seabed interaction. J. Geotech. Geoenviron. Eng. 132 (7), 842-851.

Craig, R.F., 2004. Craig's Soil Mechanics, seventh ed. E \& FN Spon, London \& New York. Das, B.M., 2008. Advanced Soil Mechanics, third ed. Taylor \& Francis, New York.

Groot, M.B.de, Kudella, M., Meijers, P., Oumeraci, H., 2006. Liquefaction phenomena underneath marine gravity structures subjected to wave loading. J. Waterw. Port, Coast. Ocean Eng. 132, 325-335.

Gratiot, N., Mory, M., 2000. Wave induced sea bed liquefaction with application to mine burial. In: Proc. of 10th Int. Offshore and Polar Engineering Conf., pp. 600-605.
Higuera, P., Lara, J.L., Losada, I.J., 2014. Three-dimensional interaction of waves and

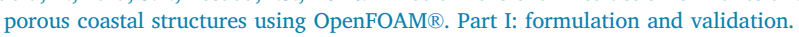
Coast. Eng. 83, 243-258.

Hsu, J.R.C., Jeng, D.S., 1994. Wave-induced soil response in an unsaturated anisotropic seabed of finite thickness. Int. J. Numer. Anal. Meth. GeoMech. 18 (11), 785-807.

Law, A.W.K., 1993. Wave-induced effective stress in seabed and its instantaneous liquefaction. Discussion to the paper by Sakai et al. (1992). J. Waterw. Port, Coast. Ocean Eng. 119 (6), 694-695.

Liu, B., Jeng, D.S., Ye, G.L., Yang, B., 2015. Laboratory study for pore pressures in sandy deposit under wave loading. Ocean Eng. 106, 207-219.

Liu, Y., Niu, X.J., Yu, X.P., 2011. A new predictive formula for inception of regular wave breaking. Coast. Eng. 58 (9), 877-889.

Madsen, O.S., 1978. Wave-induced pore pressures and effective stresses in a porous bed. Geotechnique 28 (4), 377-393.

Mase, H., Sakai, T., Sakamoto, M., 1994. Wave-induced porewater pressures and effective stresses around breakwater. Ocean Eng. 21 (4), 361-379.

Mei, C.C., Foda, M.A., 1981. Wave-induced responses in a fluid-filled poro-elastic solid with a free surface - a boundary layer theory. Geophys. J. Int. 66 (3), 597-631. 
Michallet, H., Mory, M., Piedra-Cueva, I., 2009. Wave-induced pore pressure measurements near a coastal structure. J. Geophys. Res. 114 (C6), C06019.

Mory, M., Michallet, H., Bonjean, D., et al., 2007. A field study of instantaneous liquefaction caused by waves around a coastal structure. J. Waterw. Port, Coast. Ocean Eng. 133 (1), 28-38.

Moshagen, H., Torum, A., 1975. Wave induced pressures in permeable seabeds. J. Waterw. Harb. Coast. Eng. Div. 101 (1), 49-57.

Nago, H., Maeno, S., 1987. Pore pressure and effective stress in a highly saturated sand bed under water pressure variation on its surface. Nat. Disaster Sci. 9 (1), 23-35.

Putnam, J.A., 1949. Loss of wave energy due to percolation in a permeable sea bottom. Trans. Am. Geophys. Union 30 (3), 349-356.

Qi, W.G., Gao, F.P., 2014. Physical modeling of local scour development around a largediameter monopile in combined waves and current. Coast. Eng. 83, 72-81.

Qi, W.G., Gao, F.P., 2015. A modified criterion for wave-induced instantaneous liquefaction of sandy seabed. Theor. Appl. Mech. Lett. 5 (1), 20-23.

Qi, W.G., Shi, Y.M., Gao, F.P., 2017. Poro-elastoplastic modelling of uplift resistance of shallowly-buried pipelines. In: Proc. of the ASME 2017 36th Int. Conf. on Ocean, Offshore and Arctic Eng. Trondheim, Norway. No: OMAE2017-61128.

Sakai, T., Hatanaka, K., Mase, H., 1992. Wave-induced effective stress in seabed and its instantaneous liquefaction. J. Waterw. Port, Coast. Ocean Eng. 118 (2), 202-206.

Scholtès, L., Chareyre, B., Michallet, H., et al., 2015. Modeling wave-induced pore pressure and effective stress in a granular seabed. Continuum Mech. Therm. 27 (1-2), 305-323.
Sui, T.T., Zhang, C., Guo, Y.K., Zheng, J.H., Jeng, D.S., Zhang, J.S., Zhang, W., 2016. Three-dimensional numerical model for wave-induced seabed response around mono-pile. Ships Offshore Struct. 11, 667-678.

Sui, T.T., Zheng, J.H., Zhang, C., Jeng, D.S., Zhang, J.S., Guo, Y.K., He, R., 2017. Consolidation of unsaturated seabed around an inserted pile foundation and its effects on the wave-induced momentary liquefaction. Ocean Eng. 131, 308-321.

Sumer, B.M., 2006. Editorial: special issue on liquefaction around marine structures. J. Waterw. Port, Coast. Ocean Eng. 132 (4), 225.

Sumer, B.M., 2014. Liquefaction Around Marine Structures. World Scientific, Singapore. Sumer, B.M., Fredsøe, J., Christensen, S., Lind, M.T., 1999. Sinking/floatation of pipelines and other objects in liquefied soil under waves. Coast. Eng. 38, 53-90.

Tørum, 2007. Wave-induced pore pressures - air/gas content. J. Waterw. Port, Coast. Ocean Eng. 133 (1), 83-86.

Ulker, M.B.C., Rahman, M.S., Jeng, D.S., 2009. Wave-induced response of seabed: various formulations and their applicability. Appl. Ocean Res. 31 (1), 12-24.

Yamamoto, T., Koning, H.L., Sellmeijer, H., Hijum, E.V., 1978. On the response of a poroelastic bed to water waves. J. Fluid Mech. 87 (01), 193-206.

Zen, K., Yamazaki, H., 1990a. Mechanism of wave-induced liquefaction and densification in seabed. Soils Found. 30 (4), 90-104.

Zen, K., Yamazaki, H., 1990b. Oscillatory pore pressures and liquefaction in seabed induced by ocean waves. Soils Found. 30 (4), 147-161.

Zhang, C., Sui, T.T., Zheng, J.H., Xie, M.X., Nguyen, V.T., 2016. Modelling wave-induced 3D non-homogeneous seabed response. Appl. Ocean Res. 61, 101-114. 